there was no correlation between the effect on blood pressure and the reduction in the rate of deterioration of renal function. In two of our patients the rate of deterioration of renal function was substantially reduced, although the blood pressure was not improved.

The effect of captopril on mean urinary protein excretion was not significant, but proteinuria was reduced in most patients. Recently, Taguma et al reported that treatment with captopril reduced proteinuria in diabetic nephropathy. ${ }^{12}$ The patients in their study, however, differed from ours. They were much older and had more severe proteinuria; congestive heart failure was common among their patients but was present in none of our patients. Differences between the patients may therefore explain the different effects of captopril on proteinuria.

Captopril is an efficient and safe antihypertensive drug for patients with diabetic nephropathy. Our findings support the hypothesis that inhibition of angiotensin converting enzyme protects the kidney by its effects on renal haemodynamics.

\section{References}

1 Mogensen CE. Glomerular filtration rate and renal plasma flow in short term and long term juvenile diabetes mellitus. Scand f Clin Lab Invest 1971;28:91-100.
2 Hostetter TH, Rennke HG, Brenner BM. The case for intrarenal hypertension in the initiation and progression of diabetic and other glomerulopathies. Am f Med 1982;72:375-80.

3 Blantz RC, Konnen KS, Tucker BJ. Angiotensin II effects upon the glomerular microcirculation and ultrafiltration coefficient of the rat. $f$ Clin Invest 1976;57:419-34

4 Nordén G, Björck S, Granerus G, Nyberg G. Renal function measurement in diabetic nephropathy-evaluation of five methods. Transplant Proc (in press).

5 Hall JE, Guyton AC, Jackson TE, Coleman TG, Lohmeier TE, Trippodo NC. Control o glomerular filtration rate by renin-angiotensin system. Am J Physiol 1977;233:F366-72.

6 Christlieb AR, Kaldany A, D'Elia JA. Plasma renin activity and hypertension in diabetes mellitus. Diabetes 1976;25:969-74.

Björck S, Delin K, Herlitz $\mathrm{H}$, Larsson $\mathrm{O}$, Aurell $\mathrm{M}$. Renin secretion in advanced diabetic nephropathy. Scand f Urol Nephrol 1984;79 (suppl):53-7.

8 Weidman P, Beretta-Piccoli C, Keusch G. Sodium-volume factor, cardiovascular reactivity and hypotensive mechanism of diuretic therapy in mild hypertension associated with diabetes mellitus. Am J Med 1979;67:779-84.

9 Anderson S, Meyer TW, Rennke HG, Brenner BM. Control of glomerular hypertension limits glomerular injury in rats with reduced renal mass. $\mathcal{F}$ Clin Invest 1985;76:612-9.

10 Raii L, Chiou X, Owens R, Wrigley B. Therapeutic implications of hypertension-induced glomerular injury. Am $\mathcal{F}$ Med 1985;79(suppl 3C):37-41.

11 Zatz R, Meyer TW, Dunn BR, Anderson S, Troy JL, Brenner BM. Lowering of arterial pressure limits glomerular hypertension and albuminuria in experimental diabetes. Kidney Int 1985;27 252.

12 Taguma Y, Kitamoto Y, Futaki G, et al. Effect of captopril on heavy proteinuria in azotemic diabetics. N Engl f Med 1985;313:1617-20.

13 Wiseman MJ, Drury PL, Keen H, Viberti GC. Plasma renin activity in insulin dependent diabetes with raised glomerular filtration rate. Clin Endocrinol 1984;21:409-14.

14 Parving HH, Andersen AR, Smidt UM, Svendsen PA. Early aggressive antihypertensive treatment reduces rate of decline in kidney function in diabetic nephropathy. Lancet 1983;i:1175-8.

15 Mogensen CE. Long-term antihypertensive treatment inhibiting progression of diabetic nephropathy. BrMed J 1982;285:685-8.

(Accepted 2I May 1986)

\title{
Identifying men at high risk of heart attacks: strategy for use in general practice
}

\author{
A G SHAPER，S J POCOCK， A N PHILLIPS， MARY WALKER
}

\begin{abstract}
A strategy was devised for identifying men at high risk of acute myocardial infarction or sudden ischaemic death. A risk score was devised using cigarette smoking, mean blood pressure, recall of ischaemic heart disease or diabetes mellitus diagnosed by a doctor, history of parental death from "heart trouble," and the presence of angina reported on a questionnaire. The top fifth of the score distribution identified $53 \%$ of ischaemic heart disease cases-that is, men who subsequently experienced major ischaemic heart disease over the next five years. The addition of serum total cholesterol concentration and electrocardiographic evidence only slightly improved prediction (to $59 \%$ ) and would have considerably increased the cost and effort of screening.

Using this risk score on an opportunistic basis could be particularly valuable in general practice. Management of this high risk group is regarded as appropriate medical care and is complementary to the population approach to preventing ischaemic heart disease. Such a strategy for reducing the incidence of and mortality from ischaemic heart disease in men at high risk would also increase professional and public awareness of the need for preventive action.
\end{abstract}

\footnotetext{
Department of Clinical Epidemiology and General Practice, Royal Free Hospital School of Medicine, London NW3 2PF

A G SHAPER, FRCP, FFCM, professor of clinical epidemiology

$S$ J POCOCK, MSC, PHD, reader in medical statistics

A N PHILLIPS, MSC, PHD, statistician

MARY WALKER, SRN, SCM, research administrator

Correspondence and requests for reprints to: Professor Shaper.
}

\section{Introduction}

The United Kingdom has one of the highest death rates for ischaemic heart disease, especially in Scotland and Northern Ireland. ${ }^{1}$ This high mortality is matched by a high prevalence of ischaemic heart disease, ${ }^{2}$ and the established risk factors (raised serum total cholesterol concentration, cigarette smoking, and raised blood pressure) are common in Great Britain. ${ }^{3}$ To diminish substantially the impact of ischaemic heart disease in Britain almost certainly requires substantial and prolonged changes in the population's diet, cigarette smoking habits, blood pressure, and physical activity. Although such a population approach may be most effective in the long run, there is a current need to identify those people with a particularly high risk of suffering major events due to ischaemic heart disease. This paper aims to provide a means of identifying those men at highest risk of a heart attack in the belief that such people require appropriate medical care, both to improve their quality of life and to reduce the risk of heart attacks. This high risk approach is regarded as strictly complementary to the population approach, since it is difficult to accept one of these strategies to the exclusion of the other.

\section{Subjects and methods}

The data used were derived from the British Regional Heart Study, which examined 7735 men aged 40-59 randomly selected from the age-sex registers of representative group general practices in 24 towns in England, Wales, and Scotland. The criteria for selecting the towns, the general practices, and the subjects, as well as the methods of data collection, have been presented..$^{2-6}$ The 24 towns were selected from those with populations of 50 000-100 000; they represented the full range of cardiovascular disease mortality and included towns in all the major standard regions. The general practice selected in each town had a social class distribution representative of the town. The men were selected at random from age-sex registers; no attempt was made to exclude subjects with cardiovascular disease, and there was a $78 \%$ response rate. 
Research nurses administered a questionnaire to and completed an examination of each man. Details of blood pressure, body mass index, serum lipid concentrations, smoking behaviour, electrocardiographic abnormalities, angina noted on the questionnaire, and the man's recall of a doctor's diagnosis of heart disease have all been reported previously. ${ }^{2-6}$ In this study exposure to cigarette smoking was expressed as the number of years a man had smoked, irrespective of the quantity, as this was most strongly related to risk of ischaemic heart disease. Subjects were regarded as having angina if they had indicated on a questionnaire that chest pain was present on exertion (walking uphill or hurrying). This included definite and possible angina. ${ }^{2}$ Multivariate results in this paper are confined to the 7506 men $(97 \%)$ with complete data on all the above risk factors.

\section{FOLLOW UP}

All men initially examined in 1978-80 are being followed up for both morbidity and mortality for eight years. 5 In this analysis the follow up period for each man was five years; follow up was achieved for $99 \%$ of the original cohort. There were 276 cases of fatal or non-fatal major ischaemic heart disease ( 270 of these occurred in men with complete data). A fatal case was considered to have occurred if ischaemic heart disease (ICD codes 410-414) was recorded as the underlying cause of death. In non-fatal cases a myocardial infarction was diagnosed according to World Health Organisation criteria. ${ }^{6}$

\section{Results and comment}

RISK FACTORS AND RISK OF ISCHAEMIC HEART DISEASE (UNIVARIATE ANALYSIS)

Table I shows the association of each factor with the risk of ischaemic heart disease. In this preliminary univariate presentation we considered how a subject's chance of suffering major ischaemic heart disease was associated with his observed levels of a risk factor, without taking account of interrelations with other risk factors. For each factor men were ranked in order of magnitude of the measurement and then divided into five groups of roughly equal size. For each fifth the number of cases of ischaemic heart disease was then used to calculate the risk of ischaemic heart disease occurring, expressed as cases $/ 1000 /$ year. The relative risk was expressed by the ratio of the rate for men in the highest fifth to the rate for men in the lowest fifth.

All the risk factors considered-age, serum total cholesterol, systolic and diastolic blood pressure, body mass index, and the number of years of cigarette smoking-showed an increase in the rate of ischaemic heart disease events as the level of the risk factor rose. Body mass index had a relative risk of 1.8 , and smoking years and age had relative risks of 5.1 and $4 \cdot 7$, respectively. The latter two measures were obviously associated as smoking years can only be accumulated by the passage of time. Systolic and diastolic blood pressure and serum total cholesterol concentration had similar relative risks. More important was the similarity of the rates of ischaemic heart disease events in the top fifth of each risk factor distribution-about $1 \%$ a year $(10 \cdot 0-13 \cdot 5 / 1000 /$ year -and the similarity in the percentage of "cases" in the top fifth, $28-38 \%$. Interestingly, smoking years provided the highest

TABLE I-Risk rates (per 1000/year) of major ischaemic heart disease events for risk factors by fifths of their distribution calculated among 276 "cases." For cholesterol values and smoking years, data available for only 274 and 273 patients, respectively

\begin{tabular}{|c|c|c|c|c|c|c|c|}
\hline & \multicolumn{5}{|c|}{ Distribution } & \multirow{2}{*}{$\begin{array}{l}\text { Relative } \\
\text { risk }\end{array}$} & \multirow{2}{*}{$\begin{array}{l}\% \text { Cases } \\
\text { in } \\
\text { top fifth }\end{array}$} \\
\hline & 1 (Low) & 2 & 3 & 4 & 5 (High) & & \\
\hline \multicolumn{8}{|l|}{ Age } \\
\hline $\begin{array}{l}\text { No of cases } \\
\text { Risk rate }\end{array}$ & $\begin{array}{l}18 \\
2 \cdot 4\end{array}$ & $\begin{array}{l}32 \\
4 \cdot 3\end{array}$ & $\begin{array}{l}54 \\
7 \cdot 0\end{array}$ & $\begin{array}{l}78 \\
9 \cdot 8\end{array}$ & 94 & $4 \cdot 7$ & 34 \\
\hline \multicolumn{8}{|c|}{ Total cholesterol } \\
\hline $\begin{array}{l}\text { No of cases } \\
\text { Risk rate }\end{array}$ & $\begin{array}{l}30 \\
3 \cdot 7\end{array}$ & $\begin{array}{l}36 \\
5 \cdot 2\end{array}$ & $\begin{array}{c}48 \\
6 \cdot 4\end{array}$ & $\begin{array}{l}74 \\
8 \cdot 7\end{array}$ & $\begin{array}{l}86 \\
11 \cdot 5\end{array}$ & $3 \cdot 1$ & 31 \\
\hline \multicolumn{8}{|c|}{ Systolic blood pressure } \\
\hline No of cases & 33 & 28 & 42 & 75 & 98 & $3 \cdot 0$ & 36 \\
\hline Risk rate & $4 \cdot 3$ & $3 \cdot 6$ & $5 \cdot 5$ & $9 \cdot 7$ & $12 \cdot 7$ & & \\
\hline \multicolumn{8}{|c|}{ Diastolic blood pressure } \\
\hline No of cases & 30 & 54 & 43 & 56 & 93 & $3 \cdot 1$ & 34 \\
\hline Risk rate & 3.9 & $7 \cdot 0$ & $5 \cdot 5$ & $7 \cdot 3$ & $12 \cdot 1$ & & \\
\hline \multicolumn{8}{|c|}{ Body mass index } \\
\hline $\begin{array}{l}\text { No of cases } \\
\text { Risk rate }\end{array}$ & 43 & 35 & 57 & $\begin{array}{l}64 \\
8 \cdot 2\end{array}$ & 77 & $1 \cdot 8$ & 28 \\
\hline \multicolumn{8}{|l|}{ Smoking years } \\
\hline No of cases & 24 & 38 & 46 & 62 & 103 & $5 \cdot 1$ & 38 \\
\hline Risk rate & $2 \cdot 6$ & $5 \cdot 4$ & $6 \cdot 5$ & $8 \cdot 9$ & $13 \cdot 5$ & & \\
\hline
\end{tabular}

TABLE II-Risk rates (per 1000/year) of major ischaemic heart disease events by categories of ischaemic heart disease and diabetes at initial examination, and by parental history of death from "heart trouble"

\begin{tabular}{lrrr}
\hline & Cases & Total No & Risk rate \\
\hline Angina (on questionnaire & 208 & 7112 & $5 \cdot 8$ \\
$\quad$ No & 67 & 607 & $22 \cdot 1$ \\
Yes & 183 & 6601 & $5 \cdot 5$ \\
Electrocardiographic abnormalities & 53 & 884 & $12 \cdot 0$ \\
$\quad$ None & 40 & 242 & $33 \cdot 1$ \\
Ischaemia or possible myocardial infarction & 209 & 7302 & $5 \cdot 7$ \\
$\quad$ Definite myocardial infarction & 67 & 422 & $31 \cdot 8$ \\
Recall of diagnosis of ischaemic heart disease & & & 7617 \\
$\quad$ No & 267 & 118 & $15 \cdot 3$ \\
$\quad$ Yes & 9 & & \\
Recall of diagnosis of diabetes mellitus & 177 & 5658 & $6 \cdot 3$ \\
$\quad$ No & 99 & 2077 & $9 \cdot 5$ \\
$\quad$ Yes & & & \\
Parent died of heart trouble? & & & \\
No & &
\end{tabular}

TABLE III-Full and modified risk scores for ischaemic heart disease: 270 cases out of 7506 subjects

\begin{tabular}{|c|c|c|c|c|c|c|}
\hline & \multicolumn{5}{|c|}{ Distribution } & \multirow{2}{*}{$\begin{array}{l}\% \text { Cases } \\
\text { in } \\
\text { top fifth }\end{array}$} \\
\hline & 1 (Low) & 2 & 3 & 4 & 5 (High) & \\
\hline \multicolumn{7}{|l|}{ Full score } \\
\hline No of cases & 5 & 14 & 34 & 57 & 160 & 59 \\
\hline Risk rate $/ 1000 /$ year & $0 \cdot 7$ & $1 \cdot 9$ & $4 \cdot 5$ & $7 \cdot 6$ & $21 \cdot 3$ & \\
\hline \multicolumn{7}{|l|}{ Modified score } \\
\hline No of cases & 7 & 16 & 41 & 62 & 144 & 53 \\
\hline Risk rate/1000/year & 0.9 & $2 \cdot 1$ & $5 \cdot 5$ & $8 \cdot 3$ & $19 \cdot 2$ & \\
\hline
\end{tabular}

relative risk and the greatest percentage of cases in the top fifth of the distribution.

Table II shows how the three measures of pre-existing ischaemic heart disease were associated with the subsequent risk of developing events due to ischaemic heart disease. The presence of angina (noted on a standard questionnaire) conferred a considerable increase in risk rate to over $2 \%$ a year $(22 \cdot 1 / 1000 /$ year $)$ - that is, double that observed in the top fifth of any of the standard risk factors. Electrocardiographic evidence of myocardial ischaemia or possible myocardial infarction had a risk rate similar to that seen in the top fifth of the standard risk factors-that is, about $1 \%$ a year (12.0/1000/year). Electrocardiographic evidence of a definite (old) myocardial infarction had a high risk rate, over $3 \%$ a year $(33 \cdot 1 / 1000 /$ year $)$, as did recall of a doctor's diagnosis of ischaemic heart disease $(31 \cdot 8 / 1000 /$ year). Men with such evidence of ischaemic heart disease were also likely to have raised risk factor levels, ${ }^{6}$ so that the risk rate for these measures of preexisting ischaemic heart disease was exaggerated because of their relation with the standard risk factors.

The simplest information on family history of ischaemic heart disease was to ask the man if either parent had died of "heart trouble." Table II shows that among the 2077 who replied positively the risk of ischaemic heart disease was significantly higher. By comparison with the risk factors displayed in table I, family history was a fairly weak predictor of risk of major ischaemic heart disease (relative risk 1.5 ). More detailed information on the age of parent's death and whether either parent or both had died of heart trouble did not improve the prediction of the risk of ischaemic heart disease. If a man recalled a doctor's diagnosis of diabetes mellitus he carried over twice the risk of a major ischaemic heart disease event of non-diabetic men.

\section{COMBINED EFFECT OF RISK FACTORS (MULTIVARIATE ANALYSIS)}

Prediction of cases of major ischaemic heart disease can be improved by assessing the combined effect of several risk factors and pre-existing ischaemic heart disease acting simultaneously. Such multivariate analysis allows for the fact that many of the factors are interrelated and makes it possible to assess the independent contribution of each factor to the subsequent risk of ischaemic heart disease.

The full model examined here included age, mean blood pressure ((systolic blood pressure $+(2 \times$ diastolic blood pressure $)) \div 3$ ), serum total cholesterol, years of cigarette smoking, and the presence or absence of the following: myocardial infarction or ischaemia on electrocardiogram, (definite or possible) angina, recall of a diagnosis of ischaemic heart disease or diabetes made by a doctor, and parental death from "heart trouble." 
There were 7506 men with complete data, of whom 270 had a subsequent fatal or non-fatal myocardial infarction.

This full model produced the following score for combining the effects of risk factors and pre-existing disease. The coefficients, derived from multiple logistic regression, have been simplified for practical purposes without losing predictive value. Each man's full score $=$

$5 \times$ age (years),

$+3 \times$ years of smoking cigarettes,

$+3 \times$ mean blood pressure $(\mathrm{mm} \mathrm{Hg})$,

$+41 \times$ serum total cholesterol $(\mathrm{mmol} / \mathrm{l})$

+110 if the man recalled a diagnosis of ischaemic heart disease,

+110 if there was electrocardiographic evidence of definite myocardial infarction,

+45 if there was electrocardiographic evidence of possible myocardial infarction or ischaemia,

+75 if there was evidence of angina on the questionnaire,

+40 if either parent had died of "heart trouble,"

+85 if he was diabetic.

Table III shows the distribution of the 270 men with major ischaemic heart disease events (cases) across the fifths of the score. The top fifth of the distribution contained $59 \%$ of cases, compared with only $28-38 \%$ for any risk factor used separately. The risk rate for men in this top fifth of multivariate risk was $2 \%$ a year $(21 \cdot 3 / 1000 /$ year $)$ compared with $0 \cdot 07 \%(0 \cdot 7 / 1000 /$ year $)$ in the lowest fifth.

Use of this full score in general practice would entail considerable effort as recording and evaluating an electrocardiogram and determining serum total cholesterol concentration are time consuming and costly. We have therefore developed a modified score that omits these two factors. It is also convenient to omit age as it is not a significant independent risk predictor. Each man's modified score $=$

$7 \times$ years of smoking cigarettes,

$+6.5 \times$ mean blood pressure $(\mathrm{mm} \mathrm{Hg})$,

+270 if the man recalls a diagnosis of ischaemic heart disease,

+150 if there was evidence of angina on the questionnaire,

+85 if either parent had died of heart trouble,

+150 if he was diabetic.

In this modified score the three particularly important factors were blood pressure, years of smoking, and recall of a doctor's diagnosis, each of which was a highly significant independent predictor of the risk of ischaemic heart disease (each with $p<0 \cdot 00001$ ). Evidence of angina on questionnaire was also a highly significant contributor $(p=0.001)$, while family history and diabetes were less so $(p=0.02$ and $p=0.07$, respectively).

Table III shows how the cases of ischaemic heart disease were distributed across the fifths of this modified score. Compared with the full score the percentage of cases in the top fifth fell from 59\% to 53\%. The number of cases in the lowest two fifths increased from 19 to 23 . For all practical purposes, however, there seemed to be little loss of discrimination as a result of removing serum total cholesterol, electrocardiographic findings, and age from the score. When used to identify men in the top $10 \%$ of risk the full score yielded 104 cases (39\%) and the modified score 94 cases (35\%).

\section{THE RISK SCORE IN PRACTICE}

Any practical implementation of the above scores to identify middle aged men at high risk of ischaemic heart disease requires a knowledge of the distribution of each score in a representative sample. Table IV presents the decile cut off values for each score when applied to the 7506 men with full data available in the regional heart study. The value of these cut offs lies in enabling one to identify any individual man's risk of ischaemic heart disease. Note that both scores have been arranged to have a top quintile of 1000 , as an aid to ready identification of people at high risk. A few examples of people in the regional heart study are considered.

Example 1-A man aged 56 from Scunthorpe had smoked for 33 years. His body mass index was $23.8 \mathrm{~kg} / \mathrm{m}^{2}$, blood pressure $200 / 93 \mathrm{~mm} \mathrm{Hg}$, and serum total cholesterol concentration $8.7 \mathrm{mmol} / \mathrm{l}(337 \mathrm{mg} / 100 \mathrm{ml})$. He had no evidence of pre-existing ischaemic heart disease but one parent had died of "heart trouble." His full score was

$$
5 \times 56+3 \times 33+3 \times\left(\frac{200+(2 \times 93)}{3}\right)+41 \times 8 \cdot 7+40=1162 .
$$

This put him well into the top tenth of risk. His modified score was 1152 , which was still in the top tenth. Thus without knowledge of his high serum total cholesterol he was still classified as being at very high risk.

Example 2-A man aged 50 from Southport had angina noted both on a questionnaire and by his general practitioner. A lifelong non-smoker, his electrocardiogram was normal, his serum cholesterol concentration was $6.6 \mathrm{mmol} / \mathrm{l}(253 \mathrm{mg} / 100 \mathrm{ml})$, blood pressure was $128 / 81 \mathrm{~mm} \mathrm{Hg}$, body mass index was $21.8 \mathrm{~kg} / \mathrm{m}^{2}$, and neither parent had died of heart trouble. The preexisting ischaemic heart disease was enough to put him into the top fifth of
TABLE IV-Deciles for full and modified risk scores in 7506 men

\begin{tabular}{ccccc}
\hline Deciles & Full score & $\begin{array}{c}\text { Estimated } \\
\text { rate of risk/1000/year }\end{array}$ & Modified score & $\begin{array}{c}\text { Estimated } \\
\text { rate of risk }\end{array}$ \\
\hline 10th & 775 & $1 \cdot 5$ & 647 & $1 \cdot 8$ \\
20th & 816 & $2 \cdot 0$ & 713 & $2 \cdot 4$ \\
30th & 849 & $2 \cdot 7$ & 766 & $3 \cdot 1$ \\
40th & 879 & $3 \cdot 4$ & 812 & $3 \cdot 9$ \\
50th & 907 & $4 \cdot 3$ & 856 & $4 \cdot 8$ \\
60th & 933 & $5 \cdot 4$ & 998 & $5 \cdot 8$ \\
70th & 961 & $6 \cdot 9$ & 1000 & $7 \cdot 1$ \\
80th & 1000 & $9 \cdot 3$ & 1091 & $9 \cdot 2$ \\
90th & 1060 & $14 \cdot 7$ & & $13 \cdot 5$ \\
\hline
\end{tabular}

TABLE V-Risk characteristics in the top fifth of the full and modified scores

\begin{tabular}{lccc}
\hline \multicolumn{1}{c}{ Risk characteristic } & \multicolumn{2}{c}{$\begin{array}{c}\text { No of men with characteristics } \\
\text { in top fifth of: }\end{array}$} \\
\cline { 2 - 3 } & Modified score & Full score & Total \\
\hline Recall of diagnosed ischaemic heart disease & 373 & 362 & 404 \\
Definite myocardial infarction on electrocardiogram & 144 & 198 & 235 \\
Ischaemia or possible myocardial infarction on & 269 & 364 & 861 \\
$\quad$ electrocardiogram & 423 & 399 & 586 \\
Angina on questionnaire & 929 & 849 & 3109 \\
Current smoker & 348 & 578 & 1454 \\
Serum total cholesterol $\geqslant 7 \cdot 2 \mathrm{mmol} / 1$ & 806 & 718 & 1933 \\
Diastolic blood pressure $\geqslant 90 \mathrm{~mm} \mathrm{Hg}$ & 815 & 717 & 1645 \\
Systolic blood pressure $\geqslant 160 \mathrm{~mm} \mathrm{Hg}$ & 694 & 449 & 1510 \\
Body mass index $\geqslant 27 \cdot 9 \mathrm{~kg} / \mathrm{m}^{2}$ & 59 & 636 & 2011 \\
Parent died of heart trouble & 1501 & 1501 & 7506 \\
Recall of diagnosed diabetes & & & \\
\hline Total No of men & & & \\
\hline
\end{tabular}

Conversion: SI to traditional units-Cholesterol: $1 \mathrm{mmol} / \mathrm{l} \approx 38.7 \mathrm{mg} / 100 \mathrm{ml}$.

risk; his modified score was 1051. Using the full score, his normal electrocardiogram left him just outside the top fifth with a full score of 997 .

Example 3-A man aged 45 from Gloucester had a serum total cholesterol concentration of $8.5 \mathrm{mmol} / \mathrm{l}(329 \mathrm{mg} / 100 \mathrm{ml})$, no indications of pre-existing ischaemic heart disease, blood pressure $130 / 70 \mathrm{~mm} \mathrm{Hg}$, and body mass index $26.2 \mathrm{~kg} / \mathrm{m}^{2}$; neither parent had died of heart trouble, and he was not currently smoking cigarettes (though he had previously done so for 14 years). Despite his high serum total cholesterol value, this man's full risk score of 886 was slightly below average. As the serum total cholesterol value does not contribute to the modified score, this man's modified score of 683 was in the lowest fifth. Thus a high concentration of serum total cholesterol is not enough by itself to place this man at high risk of ischaemic heart disease relative to other men in this population.

\section{PROFILE OF MEN AT HIGH RISK}

Table $\mathrm{V}$ shows the number of men in our sample with various risk characteristics who fell into the top fifth of risk using either the modified or full scores. Clearly, large numbers of men with at least one risk characteristic will not achieve the "high risk" category, emphasising the need for a complementary population approach to the control of risk factors.

It might be held that men with a recall of diagnosed ischaemic heart disease are already known to their general practitioners and can be regarded as already receiving special attention. Although $92 \%$ of these men fell into the top fifth of the modified risk score, they comprised only $373(25 \%)$ of the 1501 men in the top fifth.

Men with a definite myocardial infarction seen on their electrocardiogram were also likely to be in the top fifth of risk, especially for the full score, to which it made a highly significant contribution. Angina on questionnaire and ischaemia on electrocardiogram were less powerful predictors of ischaemic heart disease risk, though most men with angina were in the top fifth of both risk scores. Interestingly, half the men with angina noted on chest pain questionnaires had no recall of a diagnosis by their general practitioner of ischaemic heart disease or any other heart trouble, and their problem would be presented to the general practitioner for the first time.

The three indicators of pre-existing ischaemic heart disease (recall, electrocardiogram, and chest pain) were positively associated-that is, men with one indicator were quite likely to have the others. Overall, the top fifth of the full score included 652 men $(43 \%)$ with no indication of pre-existing ischaemic heart disease and a further 227 men (15\%) whose only indication was ischaemia or possible infarction on their electrocardiogram. For the 
modified score, which did not use an electrocardiogram, the top fifth included 754 men $(50 \%)$ with no indications of ischaemic heart disease.

Well over half the men in the top fifth (modified score) were current cigarette smokers, and raised systolic and diastolic blood pressures were also common. Twenty nine per cent of the high risk men were substantially overweight (body mass index $\geqslant 27.9 \mathrm{~kg} / \mathrm{m}^{2}$, the top quintile for all men). Moderate rises in serum total cholesterol $(\geqslant 7.2 \mathrm{mmol} / 1$, the top fifth for all men) occurred in $578(39 \%)$ of men in the top fifth of the full score but in only $348(23 \%)$ of men in the top fifth of the modified score. This difference arose because concentrations of serum total cholesterol were excluded from the modified score.

\section{DIFFERENCES BETWEEN GENERAL PRACTICES}

There is an appreciable geographical variation in morbidity and mortality from ischaemic heart disease. ${ }^{7}$ Also, general practices in a given area may serve sectors of the community at differing risks of ischaemic heart disease. When the full or modified scores are used in any particular practice, therefore, the percentages of men falling above the top fifth scores defined in table IV may differ considerably from the overall $20 \%$. As a guide to such variation between practices, the extremes in our 24 practices were Guildford and Carlisle, with $9 \%$ and $29 \%$ of men respectively in the top fifth of the modified score.

\section{Discussion}

Ischaemic heart disease is a problem of epidemic proportions in many highly industrialised societies, and it is widely accepted that the key factors related to its development include raised concentrations of serum total cholesterol, raised blood pressure, and cigarette smoking. ${ }^{8}$ There is increasing agreement that a strategy for preventing ischaemic heart disease must be directed towards whole populations, with emphasis on changes in national diets, control or prevention of hypertension, and reduction in cigarette smoking. ${ }^{89}$ This population strategy implies the need for sustained effort by government and regional and district health authorities on several different fronts, with little immediate or dramatic reward for individuals or populations. If we accept this rather depressing scenario for the immediate future of ischaemic heart disease in Great Britain how do we proceed?

\section{MASS SCREENING FOR HIGH RISK PEOPLE}

The population strategy for preventing ischaemic heart disease proposes measures that affect the whole population regardless of individual levels of risk. An alternative approach is to screen each person for the major risk factors and then to focus active intervention on those at highest risk of ischaemic heart disease. There is general agreement about the need to screen for raised blood pressure because of the increased risks it carries for ischaemic heart disease, stroke, heart failure, and renal failure. In Great Britain this is most appropriately carried out in general practice.

Most people visit their general practitioner at least once in five years, and management of hypertension is mainly carried out by general practitioners. Smoking habits should be inquired about and recorded for patients, and attempts made to discourage smoking.

\section{SERUM TOTAL CHOLESTEROL}

The National Institute of Health Consensus Development Conference (United States of America) has recommended that "all physicians should be encouraged to include, whenever possible, a blood cholesterol measurement on every adult patient when that patient is first seen." 10 In Great Britain it has been suggested that "we should aim at identifying those above the 80 th percentile of the distribution of serum cholesterol concentrations and blood pressure measurement." These suggestions imply the need to measure total cholesterol in the whole adult population, albeit on an opportunistic basis.

We have shown that identifying the top $20 \%$ for serum total cholesterol in Great Britain would identify only a third of those who would develop a major ischaemic heart disease event within the next four years. The cost and resource implications of screening and rescreening the whole population are enormous and seem to be wholly unjustified. In Britain we know the distribution of serum total cholesterol in middle aged men, ${ }^{12}$ we know that it is considerably higher than concentrations in middle aged Americans, ${ }^{13}$ and we know that most British men have concentrations that carry at least a twofold risk of ischaemic heart disease compared with lower concentrations of total cholesterol. ${ }^{6}$ The exclusion of serum total cholesterol from the modified scoring system should in no way diminish the fundamental importance of this factor and its dietary associations in determining the risk of ischaemic heart disease in the community as a whole.

\section{BODY MASS INDEX}

Body mass index is clearly an indicator of increased risk in univariate analysis (table I). In multivariate analysis the importance of body mass index is considerably diminished because of its relation with blood pressure and serum total cholesterol concentration. Body mass index, therefore, has not been included in the scoring system as it does not improve prediction of major ischaemic heart disease even when serum total cholesterol concentration is removed from the modified score. Nevertheless, body mass index should be determined in every patient for reasons of action rather than prediction. Reduction in body weight by appropriate changes in diet and physical activity can lower serum total cholesterol concentration and blood pressure, as well as improving the control of diabetes mellitus. In this population an increased body mass index may be the most clinically obvious indication of increased risk of ischaemic heart disease. Like serum total cholesterol, its exclusion from the scoring system should in no way diminish its importance in the pathogenesis of ischaemic heart disease in the British community.

\section{SELECTIVE SCREENING}

The need to help people currently at high risk of acute major ischaemic heart disease includes those who already have evidence of ischaemic heart disease. They require appropriate medical care as well as active intervention towards reducing their risk. We believe it is essential to include such men with pre-existing ischaemic heart disease in the screening and scoring system. A substantial proportion of these men are not already known to their doctor and are not, therefore, under appropriate management. Their inclusion brings such men to the full attention of the general practitioner and should improve their management.

We have observed that men developing major ischaemic heart disease have the same risk factor levels whether or not they have evidence of pre-existing ischaemic heart disease, and these levels are higher than those in men who do not develop major ischaemic heart disease events. ${ }^{6}$ As pre-existing ischaemic heart disease is a powerful predictor for a subsequent event, the effect of the standard risk factors (smoking, raised blood pressure, and serum total cholesterol concentrations) must be diminished proportionately in those with pre-existing ischaemic heart disease. Nevertheless, these men are at high absolute risk of new major ischaemic heart disease events, and efforts to reduce their risk factors are important. In the Belgian heart disease prevention project the results of multifactorial intervention (diet, cigarette smoking, obesity, exercise, and blood pressure control) were strikingly more effective in men with an ischaemic electrocardiogram at baseline examination than in men with a normal electrocardiogram at baseline ${ }^{14}$ Indeed, $46 \%$ of the total benefit in reducing the incidence of ischaemic heart disease occurred in the $6.7 \%$ of men with an ischaemic electrocardiogram at entry.

\section{ACTION IN GENERAL PRACTICE}

We suggest that the modified score should be determined for all men aged about $40-60$ years who attend the practice for any reason 
whatsoever. This could be undertaken by a practice nurse or health aide, who would administer an appropriate questionnaire (on smoking, angina, recall of diagnoses, and family history), make the necessary measurements (height, weight, and blood pressure), and calculate the score. The patient would then proceed to his prearranged consultation with the doctor, who would have available the detailed observations and the risk score. The nature of the consultation should be altered by the knowledge that a man is at high risk of ischaemic heart disease. It becomes a special consultation. If facilities and opportunities allow it would be of considerable advantage to measure the serum total cholesterol concentration in the group of men selected as high risk on the modified score as an aid to individual management. Those men identified as being at high risk should make repeat visits, annually at first and then biannually, to assess any changes made and to reinforce the health education.

This presentation is primarily concerned with the identification of high risk men in general practice, but there is no reason why the same system, using either the full or the modified scores, should not be used in other situations-for example, occupational health, health screening programmes, well man clinics, and cardiac clinics.

\section{THE INDIVIDUAL AT HIGH RISK}

It must be clearly understood that the screening system enables us to place a person in a group with a high risk of major ischaemic heart disease. It does not allow us to make a precise prediction that a specific individual will or will not have a major ischaemic heart disease event within a limited period. Considering the pathology of the arterial disease present ${ }^{15}$ and the variety of possible alterations in blood characteristics, particularly thrombogenic and thrombolytic factors ${ }^{16}$ this is not particularly surprising. Nevertheless, management in high risk people has to be tailored to personal characteristics. The man in example 1 will receive advice on smoking and diet, have his blood pressure treated if it remains raised, and should have his total cholesterol concentration measured. The man in example 2 requires continued treatment of angina, will receive dietary advice, and should also have his total cholesterol concentration measured. The man in example 3 was not in the high risk group. He would be encouraged by the nurse to reduce weight by an appropriate diet, which would indirectly lower his blood cholesterol. The role of the doctor for many of the high risk subjects is to use the consultation to emphasise the need for changes to be made, and thereafter much of the persuasion will rest with the practice nurse or health aide and community and national health education.

It is evident from table $\mathrm{V}$ that selecting a high risk group for special attention excludes most men who smoke, are overweight, or have raised total cholesterol concentrations and half of those with raised blood pressure. This emphasises the prime need for a population strategy aimed at the prevention and control of these risk factors and a practice approach which uses health nurses and other aides for individual health counselling and education.

\section{WOMEN}

In Great Britain women are at considerably less risk of ischaemic heart disease than men, particularly in the younger age groups. In part, this is associated with lower rates of cigarette smoking, but the protection associated with menstrual (ovarian) function is probably important. It is difficult to provide guidelines for the screening of women as we have no British data on which to base a risk score. Women have an increased risk of ischaemic heart disease, however, during and after the menopause, so this point could serve as a guideline for entry into any ischaemic heart disease screening system. As many women are already attending screening clinics for cervical and breast cancer, the scoring system should possibly be used in those clinics.

\section{REPRODUCIBILITY OF THE SCORING SYSTEM}

It is well recognised that application of a predictive score to the same set of data from which it was derived can artificially inflate the score's discriminatory power. Given the large data set available to us, however, we consider that such inflation should be fairly small in this case. To investigate this problem we have used a simulation technique of cross validation-that is, by repeatedly estimating such a score on a random half of our data and testing its prediction on the other half. This was replicated 15 times, and on average the percentage of cases identified in the top fifth of men $(59 \%$ in table III) was attenuated by only $3 \%$.

Moreover, as only a limited number of established risk factors were used, there is little likelihood that the process of selecting factors could have led to any artificial inflation of their contribution to the predictive score. The predictive power of the risk score depends on the reliability of risk factor measurement in the practical setting. Poor standardisation of blood pressure measurement could reduce the predictability of the scoring system and poorly standardised use of the angina questionnaire could also reduce the ability to detect men at high risk of ischaemic heart disease.

\section{IS IT WORTH THE EFFORT?}

The top fifth of any single risk factor distribution carries about a $1 \%$ risk of major ischaemic heart disease a year. Using a combination of risk factors increases this risk to about $2 \%$ a year for men in the top fifth of the modified score. The average general practitioner will have about 300 middle aged men in his practice, of whom 60 are, by definition, at high risk. At an attack rate of $2 \%$ a year he will expect one case of major ischaemic heart disease from this group each year. A $20 \%$ reduction in risk would lead to the prevention of one event every five years in the 60 "high risk" men. Comparisons are difficult, but this is three times the number of strokes prevented by treating an equivalent number of people with mild hypertension ${ }^{17}$ and 10 times the number of lives saved from breast cancer by mammographic screening. ${ }^{18}$ Thus the identification of men at high risk of ischaemic heart disease may be at least as effective as these two procedures.

All of these men have attended the practice and will be seen by a doctor. The rewards for recording the basic information required for the modified scoring system are likely to be far greater than the estimate of lives saved suggests. All disorders relating to cigarette smoking and raised blood pressure are likely to benefit; dietary advice should reduce blood cholesterol concentrations, and the doctor will have his attention focused on the risk factor state of those with existing ischaemic heart disease and diabetes mellitus. All this reflects good clinical practice. There is no simple way of calculating the ultimate benefits. We may have to accept the present state of knowledge, which provides considerable evidence on the fundamental part our current national diet plays in the development of ischaemic heart disease. ${ }^{19}$ Cigarette smoking, hypertension, and diabetes mellitus are potent risk factors for ischaemic heart disease, and the whole process is started early in life.$^{20}$ Expectations of rapid or spectacular reductions in the incidence of ischaemic heart disease in middle aged men are not likely to be realised. Although the full impact of our current efforts at prevention may well belong to subsequent generations, we cannot ignore the problems of the present.

The British Regional Heart Study is a research group of the British Heart Foundation and also receives support from the Medical Research Council and the Department of Health and Social Security. Serum total cholesterol measurements were carried out in the Wolfson Research Laboratories (Professor T P Whitehead) supported by the Department of Health and Social Security. Computerised electrocardiography (Dr P W Macfarlane, University Department of Medical Cardiology, Royal Infirmary, Glasgow) was supported by the Scottish Home and Health Department and the Greater Glasgow Health Board.

\section{References}

1 Thom TJ, Epstein FH, Feldman JS, Leaverton PE. Trends in total mortality and mortalitv from heart disease in 26 countries from 1950-1978. Int 7 Epidemiol 1986;14:510-20.

Shaper AG, Cook DG, Walker M, Macfarlane PW. Prevalence of ischaemic heart disease in middle aged British men. Br Heart f 1984;51:595-605. 
3 Shaper AG, Pocock SJ, Walker M, Cohen NM, Wale CJ, Thomson AG. British Regional Heart Study: cardiovascular risk factors in middle aged men in 24 towns. Br Med 7 1981;283:179-86. 4 Shaper AG, Cook DG, Walker M, Macfarlane PW. Recall of diagnosis by men with ischaemic heart disease. Br Heart $\mathcal{O}$ 1984;51:606-11.

5 Walker $M$, Shaper AG. Follow-up of subjects in prospective studies in general practice. $\mathcal{F} R$ Coll Gen Pract 1984;34:365-70.

6 Shaper AG, Pocock SJ, Walker M, Phillips A, Whitehead TP, Macfarlane PW. Risk factors for ischaemic heart disease: the prospective phase of the British Regional Heart Study. I Epidemiol Community Health 1985;39:197-209.

7 Shaper AG. Geographic variations in cardiovascular mortality in Great Britain. Br Med Bull 1984;40:366-73.

8 World Health Organisation. Prevention of coronary heart disease. Geneva: WHO, 1982. (Technical Report Series No 678.)

9 Rose G. Strategy of prevention: lessons from cardiovascular disease. Br Med $\mathcal{J} 1981 ; 282: 1847-51$. 10 Anonymous. Consensus conference: lowering blood cholesterol to prevent heart disease. fAMA

1985;253:2080-6.
11 Oliver MF. Strategies for preventing and screening for coronary heart disease. Br Hean $\mathrm{f}$ 1985;54:1-5.

12 Thelle DS, Shaper AG, Whitehead TP, et al. Blood lipids in middle aged British men. Br Hear f 1983;49:205-13.
13 Shaper AG, Pocock SI. British blood cholesterol values and the American consensus. Br Med 7 1985;291:480-1.

14 Kornitzer M, De Backer G, Dramaix M, et al. Belgian heart disease prevention project: incidence and mortality results. Lancet 1983; i: 1066-70.

15 Davies MJ, Thomas AC. Review: plaque fissuring - the cause of acute myocardial infarction, sudden ischaemic death, and crescendo angina. Br Heart $\mathcal{1}$ 1985;53:363-73.

16 Meade TW, Chakrabarti R, Haines AP, North WRS. Characteristics affecting fibrinolytic activity and plasma fibrinogen concentrations. BrMed $\mathcal{J}$ 1979;i:153-6.

17 Medical Research Council Working Party. MRC trial of treatment of mild hypertension; principal results. Br Med f 1985;291:97-104.

18 Taber L, Fagerberg CJG, Gad A, et al. Reduction in mortality from breast cancer after mass screening with mammography. Lancet $1985 ; 1: 829-32$.

19 Committee on Medical Aspects of Food Policy, Panel on Diet in Relation to Cardiovascular Disease. Diet and cardiovascular disease. London: DHSS, 1984.

20 Joint Working Party of the Royal College of Physicians of London and the British Cardiac Society. Prevention of coronary heart disease. $f R$ Coll Physicians Lond 1976;10:213-75.

\title{
Effect of chorionic villus sampling and early pregnancy counselling on uptake of prenatal diagnosis
}

\author{
P D KNOTT, R H T WARD, M K LUCAS
}

\begin{abstract}
An early pregnancy counselling clinic was introduced to improve the uptake of prenatal diagnosis and to offer chorionic villus sampling to women aged 38 and over by their expected date of delivery. Ninety eight $(62 \%)$ unselected older mothers were seen before 11 weeks' gestation, and $23(32 \%)$ of those with viable pregnancies elected to undergo chorionic villus sampling compared with $38(52 \%)$ electing amniocentesis. A quarter of the patients booking before 11 weeks had a miscarriage.

Because of the future potential demand for chorionic villus sampling counselling during pregnancy and referral of eligible patients should occur as early as possible.
\end{abstract}

\section{Introduction}

Although the association between Down's syndrome and maternal age was established by Penrose in 1933, ' it was not until 1966 that successful karyotyping from cells in amniotic fluid was reported. ${ }^{2}$ Since then amniocentesis has become widely available to older mothers for prenatal diagnosis. Although the newer techniques monitored by ultrasound have reduced complications, ${ }^{3}$ the risk to the fetus is still estimated to be about $0.5 \%$.

The major disadvantage of amniocentesis is that it is most safely performed after 16 weeks' gestation so that termination of pregnancy, if necessary, is late, which has associated disadvantages. This may be a reason for the uptake of amniocentesis in the population at risk being lower than expected. ${ }^{6}$ Chorionic villus sampling was introduced at University College Hospital for the diagnosis of thalassaemia in 1982, but more recently the technique

Department of Obstetrics and Gynaecology, Faculty of Clinical Sciences, University College London, London WC1E 6HX

P D KNOTT, MRCOG, research fellow in perinatology

R H T WARD, MA, FRCOG, consultant obstetrician

Galton Laboratory, Department of Genetics and Biometry, Wolfson House,

University College London, London NW1 2HE

M K LUCAS, MB, DCH, consultant clinical geneticist

Correspondence to: Dr Knott. has also been used as an alternative to amniocentesis for genetic screening. We studied the impact of introducing fetal diagnosis during the first trimester for mothers at risk of delivering a chromosomally abnormal baby due to advanced age.

\section{Patients and methods}

At University College Hospital prenatal diagnosis is offered to all patients who will be 38 or over by their expected date of delivery. These mothers are seen at a special booking clinic within one week of referral to the hospital for antenatal care. Before counselling and the booking interview an ultrasound scan is performed to determine gestational age and exclude multiple or nonviable pregnancies.

The patient and her partner (if present) are then seen by one of two counsellors (PK and ML). If the pregnancy is of less than 11 weeks' gestation they are offered a choice of chorionic villus sampling, amniocentesis, or no test. They are told about the risks of a chromosomal abnormality and the advantages and disadvantages of the tests available. During this study we quoted the risks of miscarriage as being $0.5 \%$ greater than the background incidence of miscarriage for amniocentesis and $1-2 \%$ greater for chorionic villus sampling (based on local and international experience). Patients are also told that chorionic villus sampling occasionally fails to produce a result but that in these circumstances amniocentesis is still possible. They are then allowed to consider their decision at home before any tests are arranged.

Chorionic villus sampling is performed between the eighth and completed 10 th week of gestation by the transcervical route with the Portex catheter and the method previously described by Ward et al. ${ }^{8} \mathrm{~A}$ maximum of two attempts at aspiration are made on any one day. Amniocentesis is performed between 16 and 18 weeks. A pool of fluid is selected and a $22 \mathrm{G}$ spinal needle directed into the pool with continuous ultrasound surveillance. Amniotic fluid $(20 \mathrm{ml})$ is withdrawn and the cells are removed for culture.

Although direct preparations are possible from chorionic villus samples, at University College Hospital we culture the cells obtained from both procedures. The results are therefore available to the patients two to three weeks after the tests are performed. All patients who undergo chorionic villus sampling have an ultrasound scan at 18 weeks to exclude fetal abnormality, and thereafter the pregnancies are monitored in the antenatal clinic in the usual way.

\section{Results}

Since the introduction of the early pregnancy counselling clinic at University College Hospital 157 patients eligible for prenatal diagnosis have booked appointments. Of these, $98(62 \%)$ were seen before 11 weeks' 